\section{Cureus}

Received 08/20/2018

Review began 09/02/2018

Review ended 09/13/2018

Published 09/18/2018

\section{(C) Copyright 2018}

Rodrigues et al. This is an open access article distributed under the terms of the Creative Commons Attribution License CC-BY 3.0., which permits unrestricted use, distribution, and reproduction in any medium, provided the original author and source are credited.

\title{
Cohen Syndrome: Review of the Literature
}

Jonathan M. Rodrigues ${ }^{1}$, Hermina D. Fernandes ${ }^{1}$, Carrie Caruthers ${ }^{2}$, Stephen R. Braddock ${ }^{3}$, Alan P. Knutsen ${ }^{3}$

1. Internal Medicine, University of North Dakota School of Medicine and Health Sciences, Bismarck, USA

2. Allergy and Immunology, The Vancouver Clinic, Vancouver, USA 3. Pediatrics, Saint Louis University School of Medicine, Saint Louis, USA

$\square$ Corresponding author: Jonathan M. Rodrigues, allergy2016@gmail.com Disclosures can be found in Additional Information at the end of the article

\section{Abstract}

Cohen syndrome was initially described as a syndrome including obesity, hypotonia, mental deficiency, and facial, oral, ocular and limb anomalies. Leukopenia, especially neutropenia, was later described as a feature of Cohen syndrome. Cohen syndrome is caused by an autosomal recessive (AR) mutation of the vacuolar protein sorting 13 homolog B (VPS13B, also referred to as $\mathrm{COH} 1$ ) gene on chromosome $8 \mathrm{q} 22.2$.

Categories: Genetics, Pediatrics, Allergy/Immunology

Keywords: severe congenital neutropenia, cohen syndrome, vps13b, coh1, mishosseini-holmes-walton syndrome, hypotonia, myopia

\section{Introduction And Background}

Cohen syndrome was first described by M. Michael Cohen Jr. in two affected siblings and one isolated case and later confirmed by Carey et al. in four patients with features similar to those described by Cohen, including obesity, hypotonia, mental deficiency, and craniofacial, ocular, and limb anomalies [1-2]. Norio et al. later identified neutropenia as a consistent feature of Cohen syndrome [3]. Since then, over 100 cases of Cohen syndrome have been described, with 35 cases from Finland, where the disease has shown greater homogeneity. Cohen syndrome tends to be more heterogeneous with a wide phenotypic variability outside the Finnish cohort. Although some patients with clinical features similar to Cohen syndrome were initially described to have "Mishosseini-Holmes-Walton syndrome", it is now believed that these patients actually had Cohen syndrome, representing heterogeneity within the same syndrome [4-6].

\section{Review}

Cohen syndrome (Online Mendelian Inheritance in Man (OMIM) entry number 216550) is caused by an autosomal recessive (AR) mutation of the vacuolar protein sorting 13 homolog $B$ (VPS13B, also referred to as COH1) gene on chromosome 8q22.2. VPS13B is a transmembrane protein that is thought to function in vesicle-mediated transport and sorting of proteins within the cell and plays a role in the development and the function of the eye, hematological system, and central nervous system. Characteristic clinical features of Cohen syndrome are welldescribed and involve multiple systems as discussed below [7-10].

\section{Perinatal}

In the first report by Cohen et al., two of the three patients had decreased fetal activity [1]. This has been a consistent finding with as many as $50 \%$ of patients having decreased fetal activity 
$[1-2,7]$. Most children are born at term, but the birth weight and length are often in the 10th to 25th percentile [9]. Hypotonia can be an apparent feature in infancy and can cause significant breathing and feeding difficulty $[1,7,10-11]$. Some authors have reported a high-pitched cry possibly secondary to laryngeal abnormalities, like that seen in $5 p$ deletion (Cri-du-chat) syndrome [9, 12-14].

\section{Growth}

While low birth weight and short stature may be present, they are not essential features. Truncal obesity may develop in teenage years. It has been suggested that the term "obesity" be replaced with "abnormal truncal fat distribution" as these patients often present with an increased waist circumference but a normal body mass index (BMI) [15]. Functional studies have shown that the increased fat accumulation in patients with Cohen syndrome is due to an increased propensity of pre-adipocytes lacking VPS13B to differentiate into fat-storing cells [15]. An increased response of cells to insulin in earlier stages of differentiation leads to an accelerated expression of specific adipogenic genes [15].

\section{Development}

There is a significant delay in attaining motor milestones with the ability to walk independently arising between two to five years of age [7]. In addition, there may be a language delay with the first words uttered between one to five years of age. Many cannot speak in full sentences by age of six years [7]. All patients with Cohen syndrome have some level of intellectual disability, with up to $22 \%$ having profound delay [7]. Disordered social interactions, including difficulty making friends, using non-verbal communication, understanding feelings of others, and sharing are common [16]. Patients may have difficulty with independence and self-help, although affected individuals are usually able to eat and use the toilet independently $[12,17]$. These abnormalities seem to have an equal preponderance in males and females [16]. A cheerful disposition, friendly personality, and a high-pitched voice have also been reported [3, 7]. Antisocial, violent, destructive, rebellious, or untrustworthy behavior is rare [12]. Some children with Cohen syndrome may also be found to meet diagnostic criteria for an autism spectrum disorder [18-19]. Initiation of early intervention programs in physical therapy and occupational therapy to address motor delays and hypotonia, as well as speech/language therapy, is imperative [14]. Many cases can communicate successfully through sign language [12].

\section{Craniofacial abnormalities}

One of the inclusion criteria for the diagnosis of Cohen syndrome is the "typical facial characteristics," including microcephaly, down-slanting palpebral fissures, wave-shaped palpebral fissures, hypertelorism, thick eyebrows, thick bushy hair, low hairline, long and thick eyelashes, very short philtrum, prominent upper central incisors, open mouth appearance due to a short upper lip, maxillary hypoplasia, micrognathia, high and narrow palate, prominent root of the nose, bulbous nasal tip, and thick and poorly folded earlobes or small or absent lobules of ears $[3,7,10]$.

\section{Dentition}

In addition to the characteristic prominent upper incisors, patients may have an early periodontal breakdown, extensive alveolar bone loss, and often harbor putative pathogens more likely to be associated with periodontitis [7, 20]. A critical concern in patients with Cohen syndrome is the possibility of a difficult airway caused by characteristic craniofacial deformities and prominent upper incisors. During procedural anesthesia, it may be prudent to have the equipment to manage a difficult airway and an otolaryngologist available to provide a surgical airway if needed [21]. 


\section{Ophthalmologic}

There is progressive deterioration of vision throughout life, with early onset of progressive high-grade myopia, often requiring corrective lenses as early as two years of age. Progressive constriction of visual fields worsens visual function by the second decade of life [22-23]. Many affected adults have significant visual impairment by the age of 40 years, although total blindness is not common [7]. Myopia is mostly of the refractive-type due to high corneal and lenticular power, as a result of dysgenesis and atrophy of the cornea, ciliary body, and iris, causing iridial and zonular laxity and spherophakia [22]. Symptoms and findings in Cohen syndrome resemble retinitis pigmentosa [22, 24-26]. Other findings include mottled pigmentation of the retina, microphthalmia, microcornea, strabismus, astigmatism, shallow anterior chamber, sluggish pupillary reaction, retinal degeneration, bull's eye maculopathy, optic atrophy, chorioretinal dystrophy, peripapillary atrophy, cortical lens opacities, lens subluxation, constricted visual fields, exophthalmos, keratoconus, nyctalopia, down-slanting palpebral fissures, ptosis, and coloboma [7, 22-26]. Although rare, acute angle closure glaucoma has also been reported [24]. Retinal dystrophic changes are progressive, and ultimately, vision may be limited to counting fingers and light perception [23]. Electroretinograms often show attenuated or extinguished responses [24-25]. Early correction of visual defects, such as glasses to correct refractive errors or strabismus, has a positive effect on development [24-26]. However, there is no available effective treatment to halt the progression of pigmentary retinopathy. Patients should have periodic and detailed ophthalmologic exams to evaluate for refractive errors or retinal dystrophy.

\section{Hematologic}

Leukopenia, especially neutropenia, is a common feature of Cohen syndrome. Severe congenital neutropenia (SCN) is often present from birth and is mild to moderate, noncyclic, and non-fatal $[7,27]$. Patients may respond to bacterial infections with neutrophilic leukocytosis [27]. Although SCN may be without severe bacterial infections, other patients may have recurrent infections, aphthous ulcers, and chronic or recurrent gingivitis [27]. Bone marrow cellularity is usually normal or increased. De Ravel et al. described one patient with presumed Cohen syndrome and asymptomatic persistent thrombocytopenia; however, this finding has not been described elsewhere in the literature [28]. Hypercoagulability with deficient protein C, protein $\mathrm{S}$, and anti-thrombin III complicated by severe thrombosis have been described in two siblings; however, the diagnosis of Cohen syndrome was not firmly established by molecular testing in this report [29]. Neutropenia is correctible using recombinant human granulocyte colony stimulating factor (rHG-CSF) [14, 27]. Use of rHG-CSF would be warranted in patients with SCN and recurrent infections and/or recurrent aphthous ulcers. These individuals also need serial absolute neutrophil count (ANC) determinations to monitor for neutropenia [14].

\section{Gastrointestinal}

Feeding difficulties as neonates have been reported in as high as $75 \%$ of patients [7].

\section{Musculoskeletal}

Most patients with Cohen syndrome have slender hands and feet. Hypotonia is often first noticed in the neonatal period but becomes obvious by one year of age. Spasticity may develop at a later stage [7]. Various other musculoskeletal deformities may be seen, including cubitus valgus, genu valgum, pes planovalgus, kyphosis, scoliosis, ligamentous laxity, and articular hypermobility, many being secondary to underlying muscular hypotonia. These patients may also have single transverse palmar creases, thenar and hypothenar hypoplasia, mild syndactyly, a wide gap between first and second toes, and lumbar lordosis [10]. Juvenile rheumatoid arthritis has also been reported in association with Cohen syndrome [28]. 


\section{Neurologic}

Relatively consistent features among patients include motor incoordination or "clumsiness", brisk tendon reflexes, and muscular hypotonia $[3,7,10]$. Cerebellar hypoplasia has also been reported [30]. A magnetic resonance imaging (MRI) study done to rule out other causes of mental retardation may show an enlarged corpus callosum, which supports the diagnosis [7, 31]. Seizures and electroencephalographic (EEG) abnormalities are not typical features of Cohen syndrome, although these have been described in some cases $[1,11]$. Patients may have lowvoltage, non-irritative EEGs [7].

\section{Cardiac}

Cardiac defects reported in Cohen syndrome include decreased left ventricular function with advancing age, valvular defects (such as a floppy mitral valve and mitral regurgitation), vascular defects including a dilated descending aorta, cardiac systolic murmurs, ST segment abnormalities (ST-segment depression, T-wave inversion), essential hypertension, and pulmonary hypertension [3, 7, 29, 32-34]. Patients also tend to have decreased high-density lipoprotein (HDL) levels and often meet several criteria for metabolic syndrome [15].

\section{Endocrine}

Delayed onset of puberty is typical [2]. North et al. described identical twin girls with Cohen syndrome with precocious puberty, although this is not typical [35]. Gonadotropin deficiency, growth hormone deficiency, insulin resistance, non-insulin-dependent diabetes mellitus, and cryptorchidism have been described [1, 11, 35-40]. After elevated fat accumulation in VPS13Bdeficient cells, insulin resistance is observed through a reduction in phosphorylation of AKT (a protein kinase), which may explain the impaired glucose tolerance in some Cohen syndrome patients [15]. Thus, it may be important to monitor blood pressure, lipid metabolism parameters, fasting blood glucose levels, and glycated hemoglobin (A1C) annually. Furthermore, older patients may have an abnormal glucose tolerance despite relatively normal fasting blood glucose levels. It may, therefore, be prudent to perform oral glucose tolerance tests in adolescence, and every five years thereon.

\section{Genetics}

Cohen syndrome is an autosomal recessive disorder first mapped to the Chediak-Higashi syndrome gene (CHS1) locus of chromosome 8 by Tahvanainen et al. in 1994 [41]. COH1 (an ortholog of the VPS13B protein in Saccharomyces cerevisiae) is transcribed from 62 exons spanning a genomic region of $864 \mathrm{~kb}$ and encodes a transmembrane protein the vacuolar protein sorting 13 homolog B (VPS13B, COH1) gene on chromosome 8q22.2 [8, 42]. The translated protein VPS13B has a molecular weight of 44.8 kilodaltons $(\mathrm{kDa})$ comprised of 4,022 amino acids. VPS13B is a transmembrane protein that is thought to function in vesiclemediated transport and sorting of proteins within the cell and plays a role in the development and the function of the eye, hematological system, and central nervous system. By forming a physical and functional complex with the small GTPase RAB6 at the Golgi complex, VPS13B colocalizes with the cis-Golgi matrix protein GM130 and is integral for maintaining the structural and functional integrity of the Golgi complex [43-44]. VPS13B was also shown to play a crucial role in Golgi protein glycosylation and in endosomal-lysosomal trafficking [45]. The mechanism by which abnormalities in this protein lead to the phenotype of Cohen syndrome is currently unknown.

Cohen syndrome is a rare syndrome worldwide, but a higher concentration has been described in the Finnish, Japanese, Caucasian, Ohio Amish, Lebanese, and Jewish populations. In the latter group, the diagnosis has been controversial. A "Baloch" variant has been described in three large consanguineous Pakistani families [46]. Broad phenotypic variability has made the 
diagnosis of Cohen syndrome challenging. There is no generalized consensus on diagnostic criteria for Cohen syndrome. Horn et al. proposed the presence of at least three major criteria (intellectual disability, short stature, hypotonia, microcephaly, chorioretinal dystrophy, and narrow hands and feet) and one minor criterion (truncal obesity, neutropenia, myopia, or facial abnormalities) to establish the diagnosis of Cohen syndrome [13]. Clinical recognition of the distinctive facial dysmorphism is difficult prior to the age of six years [47-49]. Thus, it is difficult to diagnose Cohen syndrome in younger children. To overcome this obstacle, Chandler et al. proposed that in addition to significant learning disabilities, a child with Cohen syndrome had to have at least two of the following features: facial gestalt, pigmentary retinopathy, or neutropenia $\left(<2 \times 10^{-9} / \mathrm{mm}^{3}\right)$ [48]. Kolehmainen et al. proposed that patients having six of eight clinical criteria (developmental delay, microcephaly, typical Cohen syndrome facial gestalt, truncal obesity with slender extremities, overly sociable behavior, joint hypermobility, high myopia and/or retinal dystrophy, and neutropenia) could be considered to have true Cohen syndrome [8]. Patients fulfilling five or fewer criteria were considered to have "Cohen-like syndrome".

While 22 different VPS13B pathogenic genetic variants were identified in patients having "Cohen syndrome", no VPS13B pathogenic variants were identified in patients who only had "Cohen-like syndrome". Falk et al. showed that "facial gestalt" alone is an unreliable indicator of Cohen syndrome as there can be significant variability between ethnic populations [9, 14]. In contrast, features (such as retinal dystrophy, progressive high-grade myopia, microcephaly, hypotonia, joint hypermobility, intellectual disability, and global developmental delay) are consistent in patients with Cohen syndrome across ethnicities and are strong clinical indicators for establishing a diagnosis $[9,14]$. In a study by El Chehadeh et al., all patients with VPS13B mutations had either chorioretinal dystrophy or neutropenia [50]. This study also estimated that the Kolehmainen criteria had 100\% sensitivity and 77\% specificity in identifying Cohen syndrome.

\section{Conclusions}

In summary, it is important to consider a diagnosis of Cohen syndrome in children with microcephaly who present with early-onset hypotonia, neutropenia, and global developmental delay. Ophthalmologists should consider the diagnosis of Cohen syndrome in a young child with developmental delay, severe myopia, nyctalopia, and pigmentary retinopathy. The distinctive facial dysmorphism is a leading clue to establishing a diagnosis. In such children, a detailed ophthalmological exam, a complete blood count, and brain MRI should be considered. Physicians should also be mindful of complications arising from neutropenia, poor dentition, difficult airway encountered during anesthesia, and feeding difficulties as these may warrant special attention and care.

\section{Additional Information \\ Disclosures}

Conflicts of interest: In compliance with the ICMJE uniform disclosure form, all authors declare the following: Payment/services info: All authors have declared that no financial support was received from any organization for the submitted work. Financial relationships: All authors have declared that they have no financial relationships at present or within the previous three years with any organizations that might have an interest in the submitted work. Other relationships: All authors have declared that there are no other relationships or activities that could appear to have influenced the submitted work.

\section{References}

1. Cohen MM Jr, Hall BD, Smith DW, et al.: A new syndrome with hypotonia, obesity, mental 
deficiency, and facial, oral, ocular and limb anomalies. J Pediatr. 1973, 83:280-84. 10.1016/S0022-3476(73)80493-7

2. Carey JC, Hall BD: Confirmation of the Cohen syndrome. J Pediatr. 1978, 93:239-44. 10.1016/S0022-3476(78)80504-6

3. Norio R, Raitta C, Lindahl E: Further delineation of the Cohen syndrome; report on chorioretinal dystrophy, leukopenia and consanguinity. Clin Genet. 1984, 25:1-14. 10.1111/j.1399-0004.1984.tb00456.x

4. Mirhosseini SA, Holmes LB, Walton DS: Syndrome of pigmentary retinal degeneration, cataract, microcephaly, and severe mental retardation. J Med Genet. 1972, 9:193-96. 10.1136/jmg.9.2.193

5. Mendez HM, Paskulin GA, Vallandro C, et al.: The syndrome of retinal pigmentary degeneration, microcephaly, and severe mental retardation (Mirhosseini-Holmes-Walton syndrome): report of two patients. Am J Med Genet. 1985, 22:223-28.

10.1002/ajmg.1320220202

6. Norio R, Raitta C, Reynolds JF: Are the Mirhosseini-Holmes-Walton syndrome and the Cohen syndrome identical?. Am J Med Genet. 1986, 25:397-98. 10.1002/ajmg.1320250227

7. Kivitie-Kallio S, Norio R: Cohen syndrome: essential features, natural history, and heterogeneity. Am J Med Genet. 2001, 102:125-35. 10.1002/10968628(20010801)102:2<125::AID-AJMG1439>3.0.CO;2-0

8. Kolehmainen J, Wilkinson R, Lehesjoki AE, et al.: Delineation of Cohen syndrome following a large-scale genotype- phenotype screen. Am J Hum Genet. 2004, 75:122-27. 10.1086/422197

9. Falk MJ, Feiler HS, Neilson DE, et al.: Cohen syndrome in the Ohio Amish. Am J Med Genet A. 2004, 128A:23-28. 10.1002/ajmg.a.30033

10. Jones KL, Jones MC, del Campo MG: Cohen syndrome. Smith's Recognizable Patterns of Human Malformation, 7th Ed. Hummel T, Davis KJ (ed): Elsevier Saunders, Philadelphia; 2013. 280-81.

11. Goecke T, Majewski F, Kauther KD, Sterzel U: Mental retardation, hypotonia, obesity, ocular, facial, dental, and limb abnormalities (Cohen syndrome). Report of three patients. Eur J Pediatr. 1982, 138:338-40. 10.1007/BF00442512

12. Kivitie-Kallio S, Larsen A, Kajasto K, Norio R: Neurological and psychological findings in patients with Cohen syndrome: a study of 18 patients aged 11 months to 57 years. Neuropediatrics. 1999, 30:181-89. 10.1055/s-2007-973488

13. Horn D, Krebsová A, Kunze J, Reis A: Homozygosity mapping in a family with microcephaly, mental retardation, and short stature to a Cohen syndrome region on 8q21.3 - 8q22.1: redefining a clinical entity. Am J Med Genet. 2000, 92:285-92. 10.1002/(SICI)10968628(20000605)92:4<285::AID-AJMG13>3.0.CO;2-D

14. Wang H, Falk MJ, Wensel C, Traboulsi EI: Cohen syndrome. GeneReviews ${ }^{\circledR}$ (Internet). Adam MP, Ardinger HH, Pagon RA, et al. (ed): University of Washington, Seattle; 2006.

15. Limoge F, Faivre L, Gautier T, et al.: Insulin response dysregulation explains abnormal fat storage and increased risk of diabetes mellitus type 2 in Cohen syndrome. Hum Mol Genet. 2015, 24:6603-13. 10.1093/hmg/ddv366

16. Howlin P: Autistic features in Cohen syndrome: a preliminary report . Dev Med Child Neurol. 2001, 43:692-96. 10.1111/j.1469-8749.2001.tb00143.x

17. Karpf J, Turk J, Howlin P: Cognitive, language, and adaptive behavior profiles in individuals with a diagnosis of Cohen syndrome. Clin Genet. 2004, 65:327-32. 10.1111/j.13990004.2004.00229.x

18. Howlin P, Karpf J: Using the social communication questionnaire to identify 'autistic spectrum' disorders associated with other genetic conditions: findings from a study of individuals with Cohen syndrome. Autism. 2004, 8:175-182. 10.1177/1362361304042721

19. Chandler KE, Moffett M, Clayton-Smith J, Baker GA: Neuropsychological assessment of a group of UK patients with Cohen syndrome. Neuropediatrics. 2003, 34:7-13. 10.1055/s-200338617

20. Alaluusua S, Kivitie-Kallio S, Wolf J, et al.: Periodontal findings in Cohen syndrome with chronic neutropenia. J Periodontol. 1997, 68:473-78. 10.1902/jop.1997.68.5.473

21. Meng L, Quinlan JJ, Sullivan E: The anesthetic management of a patient with Cohen syndrome. Anesth Analg. 2004, 99:697-98. 10.1213/01.ANE.0000130256.42593.C5

22. Summanen P, Kivitie-Kallio S, Norio R, et al.: Mechanisms of myopia in Cohen syndrome mapped to chromosome 8q22. Invest Ophthalmol Vis Sci. 2002, 43:1686-93. 
23. Taban M, Memoracion-Peralta DS, Wang H, et al.: Cohen syndrome: report of nine cases and review of the literature, with emphasis on ophthalmic features. J AAPOS. 2007, 11:431-37. 10.1016/j.jaapos.2007.01.118

24. Kivitie-Kallio S, Summanen P, Raitta C, Norio R: Ophthalmologic findings in Cohen syndrome. A long-term follow-up. Ophthalmology. 2000, 107:1737-45. 10.1016/S01616420(00)00279-7

25. Chandler KE, Biswas S, Lloyd IC, et al.: The ophthalmic findings in Cohen syndrome . Br J Ophthalmol. 2002, 86:1395-98. 10.1136/bjo.86.12.1395

26. Mrugacz M, Sredzinska-Kita D, Bakunowicz-Lazarczyk A: Pediatric ophthalmologic findings of Cohen syndrome in twins. J Pediatr Ophthalmol Strabismus. 2005, 42:54-56.

27. Kivitie-Kallio S, Rajantie J, Juvonen E, Norio R: Granulocytopenia in Cohen syndrome. Br J Haematol. 1997, 98:308-11. 10.1046/j.1365-2141.1997.2323049.x

28. De Ravel TJL, Azou M, Fryns JR: Cohen syndrome and rheumatoid arthritis. Genet Couns. 2002, 13:63-64.

29. Schlichteimeier TL, Tomlinson GE, Kamen BA, et al.: Multiple coagulation defects and the Cohen syndrome. Clin Genet. 1994, 45:212-16. 10.1111/j.1399-0004.1994.tb04026.x

30. Waite A, Somer M, O'Driscoll M, et al.: Cerebellar hypoplasia and Cohen syndrome: a confirmed association. Am J Med Genet A. 2010, 152A:2390-93. 10.1002/ajmg.a.33569

31. Kivitie-Kallio S, Autti T, Salonen O, Norio R: MRI of the brain in the Cohen syndrome: a relatively large corpus callosum in patients with mental retardation and microcephaly. Neuropediatrics. 1998, 29:298-301. 10.1055/s-2007-973581

32. Kivitie-Kallio S, Eronen M, Lipsanen-Nyman M, et al.: Cohen syndrome: evaluation of its cardiac, endocrine and radiological features. Clin Genet. 1999, 56:41-50. 10.1034/j.13990004.1999.560106.x

33. Sack J, Friedman E: Cardiac involvement in the Cohen syndrome: a case report . Clin Genet. 1980, 17:317-19. 10.1111/j.1399-0004.1980.tb00156.x

34. Cokkinos P, Gkouziouta A, Karavolias G, et al.: Idiopathic pulmonary arterial hypertension in a young patient with the Cohen syndrome. Hellenic J Cardiol. 2013, 54:143-46.

35. North K, Fulton AB, Whiteman DAH: Identical twins with Cohen syndrome. Am J Med Genet. 1995, 58:54-58. 10.1002/ajmg.1320580112

36. Massa G, Dooms L, Vanderschueren-Lodeweyckx M: Growth hormone deficiency in a girl with the Cohen syndrome. J Med Genet. 1991, 28:48-50. 10.1136/jmg.28.1.48

37. Kumandas S, Gümüs H, Kurtoğlu S, et al.: Cohen syndrome with acanthosis nigricans and insulin resistance. J Pediatr Endocrinol Metab. 2001, 14:807-10. 10.1515/JPEM.2001.14.6.807

38. Atabek ME, Keskin M, Kurtoğlu S, Kumandas S: Cohen syndrome with insulin resistance and seizure. Pediatr Neurol. 2004, 30:61-63. 10.1016/S0887-8994(03)00309-6

39. Nambu M, Oshima Y, Kakiuchi T, et al.: Cohen's syndrome with diabetes mellitus . Acta Paediatr Jpn. 1988, 30:84-88. 10.1111/j.1442-200X.1988.tb02502.x

40. De Ravel TJL, Dillen K, Fryns JR: A new association of mental retardation, short stature, unusual face, radio-ulnar synostosis and retinal pigment abnormalities: Cohen syndrome with thrombocytopenia. Genet Couns. 2002, 13:475-76.

41. Tahvanainen E, Norio R, Karila E, et al.: Cohen syndrome gene assigned to the long arm of chromosome 8 by linkage analysis. Nat Genet. 1994, 7:201-204. 10.1038/ng0694-201

42. Kolehmainen J, Black GC, Saarinen A, et al.: Cohen syndrome is caused by mutations in a novel gene, $\mathrm{COH} 1$, encoding a transmembrane protein with a presumed role in vesiclemediated sorting and intracellular protein transport. Am J Hum Genet. 2003, 72:1359-69. $10.1086 / 375454$

43. Seifert W, Kühnisch J, Maritzen T, et al.: Cohen syndrome-associated protein, COH1, is a novel, giant Golgi matrix protein required for Golgi integrity. J Biol Chem. 2011, 286:3766575. 10.1074/jbc.M111.267971

44. Seifert W, Kühnisch J, Maritzen T, et al.: Cohen syndrome-associated protein COH1 physically and functionally interacts with the small GTPase RAB6 at the Golgi complex and directs neurite outgrowth. J Biol Chem. 2015, 290:3349-58. 10.1074/jbc.M114.608174

45. Duplomb L, Duvet S, Picot D, et al.: Cohen syndrome is associated with major glycosylation defects. Hum Mol Genet. 2014, 23:2391-99. 10.1093/hmg/ddt630

46. Rafiq MA, Leblond CS, Saqib MA, et al.: Novel VPS13B mutations in three large Pakistani Cohen syndrome pamilies suggests a Baloch variant with autistic-like features. BMC Med Genet. 2015, 16:41. 10.1186/s12881-015-0183-0 


\section{Cureus}

47. Fryns JP, Legius E, Devriendt K, et al.: Cohen syndrome: the clinical symptoms and stigmata at a young age. Clin Genet. 1996, 49:237-41. 10.1111/j.1399-0004.1996.tb03780.x

48. Chandler KE, Kidd A, Al-Gazali L, et al.: Diagnostic criteria, clinical characteristics, and natural history of Cohen syndrome. J Med Genet. 2003, 40:233-41. 10.1136/jmg.40.4.233

49. El Chehadeh-Djebbar S, Blair E, Holder-Espinasse M, et al.: Changing facial phenotype in Cohen syndrome: towards clues for an earlier diagnosis. Eur J Hum Genet. 2013, 21:736-42. 10.1038/ejhg.2012.251

50. El Chehadeh S, Aral B, Gigot N, et al.: Search for the best indicators for the presence of a VPS13B gene mutation and confirmation of diagnostic criteria in a series of 34 patients genotyped for suspected Cohen syndrome. J Med Genet. 2010, 47:549-53.

10.1136/jmg.2009.075028 